\title{
Effect on anxiety of Coriandrum sativum leaf hydroethanolic extract oil and aqueous fraction in swiss albino mice
}

\author{
Rejeesh Edavan Puthallath ${ }^{1}$, Sridevi Kotekar ${ }^{2 *}$, S. N. Rao ${ }^{2}$, \\ Megha Rani Narayana ${ }^{2}$, Roopa P. Nayak ${ }^{2}$
}

\author{
${ }^{1}$ Department of Pharmacology, Mount Zion Medical College, Adoor, Kerala, India \\ ${ }^{2}$ Department of Pharmacology, Yenepoya Medical College, Yenepoya, Mangaluru, Karnataka, India
}

Received: 04 May 2020

Accepted: 06 June 2020

*Correspondence:

Dr. Sridevi Kotekar

Email: shettysri87@gmail.com

Copyright: ( $)$ the author(s), publisher and licensee Medip Academy. This is an open-access article distributed under the terms of the Creative Commons Attribution Non-Commercial License, which permits unrestricted non-commercial use, distribution, and reproduction in any medium, provided the original work is properly cited.

\begin{abstract}
Background: Anxiety is a protective reflex and the most common disorder. This study was done to evaluate the effect of anxiolytic property of oil and aqueous fractions isolated from hydroethanolic extracts of Coriandrum sativum leaf by novel freezing technique with swiss albino mice.

Methods: Hydroethanolic extract of Coriandrum sativum leaves was prepared. Oil and aqueous part were separated with freezing technique. Animals were divided into six groups. $\mathrm{I}^{\text {st }}$ group served as control and $1 \%$ DMSO was administered orally. $\mathrm{II}^{\text {nd }}$ to $\mathrm{V}^{\text {th }}$ group were administered with Coriandrum sativum oil fraction and Coriandrum sativum aqueous fraction at doses of 400 and $800 \mathrm{mg} / \mathrm{kg}$ orally. VI ${ }^{\text {th }}$ group was treated with diazepam $1 \mathrm{mg} / \mathrm{kg}$ orally. After one hour of dosing, battery of test was done viz, elevated plus maze (EPM), light dark arena, photo actometer and rotarod.

Results: One-way analysis variance (ANOVA) followed by Dunnett's multiple comparison test was used for statistical analysis. Anxiolytic property was found to be in the following order diazepam>Coriandrum sativum aqueous 800>Coriandrum sativum aqueous 400>Coriandrum sativum oil 800>Coriandrum sativum oil $400 \mathrm{mg} / \mathrm{kg}$. All the extracts were devoid of adverse effects of motor coordination.

Conclusions: Coriandrum sativum leaf possesses anxiolytic effect. The aqueous fraction of the hydroethanolic extract of the Coriandrum sativum leaf was found to be potent and further analysis may lead to identification of active compounds. The findings that the extract is non-sedating anxiolytic and is of good safety index are promising.
\end{abstract}

Keywords: Anxiolytic, Coriandrum sativum, Elevated plus maze, Light dark arena, Swiss albino mice

\section{INTRODUCTION}

Anxiety is a normal human emotion that serves as an adaptive function from a psychobiological perspective. However, in a psychiatric setting, feeling of fear or dreads that are unfocused or out of scale with the perceived threat often requires treatment. ${ }^{1}$

According to the World health report, approximately 450 million people suffer from mental or behavioural disorders, yet only a small minority of them receives even the most basic treatment. ${ }^{2}$ This amounts to $12.3 \%$ of the global burden of disease and will rise to $15 \%$ by $2020 .^{3} \mathrm{In}$ the search for a new therapeutic products for the treatment of neurological disorders, medicinal plant research, worldwide has progressed constantly demonstrating the pharmacological effectiveness of different plant species in a variety of animal models.

Coriandrum sativum belongs to family Apiaceae. It is an annual herb and according to the climatic condition, it is 
cultivated as a summer or winter annual crop. ${ }^{4}$ The plant is named after koris, the Greek word for bug as the unripe fruits have a smell that has been compared to that of bed bugs. ${ }^{5}$ All parts of the plant are edible but fresh leaves and dried seeds are used commonly as flavouring agents for culinary purposes. In Indian traditional medicine, it is used in disorders of digestive, respiratory and urinary system as it has diaphoretic, diuretic, carminative and stimulant activities. In Iranian folk medicine, it has been indicated for dyspeptic conditions, loss of appetite, convulsions and insomnia. ${ }^{6,7}$

Most of the anxiolytic agents share common adverse effects like drowsiness and motor in-coordination affecting the quality of life. These facts express the necessity for research in the field of anxiety focusing on new therapeutic strategies. In this study Coriandrum sativum was screened for its anxiolytic property.

\section{METHODS}

\section{Collection and authentication of plant material}

Leaves of C. sativum (each of $250 \mathrm{~g}$ ) were collected from local market of Mangalore, Karnataka, India and were authenticated. The voucher specimen was submitted to Department of Pharmacology, Yenepoya University for future references.

\section{Preparation of hydroethanolic extract}

Leaves of $C$. sativum was cleaned with running tap water to remove extraneous particles and extracted using hydroethanolic (30:70) in Soxhlet apparatus at 70-80 $\mathrm{C}$ for 5 days. The extract was filtered, concentrated under reduce pressure and dried using rotary evaporator at $85^{\circ}$ $\mathrm{C}$ for 4 hours. The yield was $11.33 \%$. The extract was frozen thrice in order to separate oil and aqueous part completely. Later the extract was stored at $4^{\circ} \mathrm{C}$. The extract thus obtained was dissolved in $10 \%$ DMSO for the study.

\section{Chemicals and drugs used}

Ethanol 99.9\% manufactured by Honyon International Inc, China. Diazepam $10 \mathrm{mg}$ tablet - manufactured by Abott Healthcare Ltd, India.

\section{Animals}

36 healthy male swiss albino mice aged 3-4 months weighing 25-30 g were used in the present study. They were procured from animal house, Department of Pharmacology, Yenepoya Medical College, Mangalore. The animals were housed in polypropylene cages, four in each cage. The animals were given standard pellet diet and water ad libitum and 12 hours light and 12 hours dark cycle was maintained. The animals were acclimatized to the laboratory conditions 1 hour before experiments. The experiment was conducted in a soundproof and dimly lighted environment. The experiment was performed between 12-5 pm. Experimental protocol was approved by Institutional Animal Ethics Committee (IAEC). Care of the animals was taken as per guidelines of the committee for the purpose of control and supervision of experiments on animals (CPCSEA) India.

\section{Study design}

The animals were divided into six groups $(\mathrm{n}=6)$. Group I - control (1\% DMSO $0.1 \mathrm{ml} / 10 \mathrm{~g} /$ oral), group II to $\mathrm{V}$ - test (CS oil fraction and CS aqueous fraction at doses of 400 and $800 \mathrm{mg} / \mathrm{kg} /$ oral), and group VI - standard (diazepam $1 \mathrm{mg} / \mathrm{kg} /$ oral).

After one hour of dosing, battery of test was done viz, elevated plus maze (EPM), light dark arena (LD), Photo actometer (PA) and rotarod (RR). Acute toxicity study was done at dose of $2000 \mathrm{mg} / \mathrm{kg}$ orally and animals were observed for 14 days. The anxiety level was evaluated using the following standard test.

\section{Elevated plus maze ${ }^{8,9}$}

The elevated plus maze combines three potential anxiogenic factors - novelty, height and open space. The cross shaped maze consists of four arms that are interconnected by a central platform. The maze is suspended $50 \mathrm{~cm}$ above the ground level. The mouse was placed on the central platform facing one of the enclosed arms and observed for 5 minutes. The test was recorded using a video camera attached to a computer. During the 5 minutes test, the number of open and closed arm entries, plus the time spent in open and closed arms were recorded. The arena was cleaned with spirit after each test.

\section{Light dark arena $^{8,9}$}

The maze is divided into two parts, $1 / 3$ with opaque walls and a cover (dark compartment) whereas the remaining $2 / 3$ is open and illuminated (light compartment). The opening between the two compartments permits the mouse to move from one chamber to the other. The mouse was placed in the light compartment and observed for 5 minutes. The test was recorded using a video camera attached to a computer. During the test period, the time spent in light and dark compartment and number of crossings was recorded. The arena was cleaned with spirit after each test.

\section{Assessment of locomotor behaviour}

Photo actometer ${ }^{8,9}$

The locomotor activity can be easily measured using photo actometer, which have a square arena in which the animal moves. This apparatus operates on photo-electric cells, which are connected in circuit with a counter. When the beam of light falling on the photocell is cut off by the animal, a count is recorded. The locomotor activity 
of the mice was evaluated for 5 minutes. The arena was cleaned with spirit after each test.

\section{Assessment of muscle co-ordination}

\section{$\operatorname{Rotarod}^{10}$}

One of the important pharmacological actions of antianxiety agents of benzodiazepine class of drugs is muscle relaxant property. The skeletal muscle relaxation together with taming effect of these agents reduces anxiety and tension.

The loss of muscle grip is an indication of muscle relaxation. This effect can be easily studied in animals using rotarods. The difference in fall off time from the rotating rod between the control and diazepam treated animal is taken as an index of muscle relaxation.

The angle of the slope of inclined plane, or the rate of rotation of the rod should be adjusted such that a normal mouse can stay on the plane or on the rod for an appreciable period of time 2-5 minutes.

Mice were placed one by one on the rotating rod. Cut off time was 120 seconds. The 'fall off time' was noted when the mouse fell from the rotating rod. Three chances were given to each mouse.

\section{Statistical analysis}

The results were recorded as mean $\pm \mathrm{SD}$. All the results were analysed with one-way analysis variance (ANOVA) followed by Dunnett's multiple comparison test. $\mathrm{P}$ value less than 0.01 was considered as significant. Graph pad prism version 3.02 was used for statistical analysis.

\section{RESULTS}

Effect of hydroethanolic extract coriandrum sativum extracts on elevated plus maze

\section{Effects on anxiety}

Parameter 1 - time spent in open arm. The anxiolytic potency of the extracts in EPM test were in following order, control<leaf oil $400<$ leaf oil $800<$ leaf aqueous $800<$ leaf aqueous $400<$ diazepam (Table 1 ).

Table 1: Effect of HECS on time spent in open arm of elevated plus maze number of mice in each group.

\begin{tabular}{|ll|}
\hline Group & Time spent in open arm \\
\hline Control & $15.17 \pm 4.02$ \\
\hline Leaf oil 400 & $123.67 \pm 12.24 * *$ \\
\hline Leaf oil 800 & $149.83 \pm 35.69 * *$ \\
\hline Leaf aqueous 800 & $154.83 \pm 23.22 * *$ \\
\hline Leaf aqueous 400 & $165.00 \pm 18.95 * *$ \\
\hline Diazepam & $252.33 \pm 25.54 * *$ \\
\hline
\end{tabular}

$\mathrm{n}=6$; symbol $* *$ indicates significant values at $\mathrm{p}<0.01$ vs control.
Parameter 2 - number of entries to open arm. The anxiolytic potency of the extracts in EPM test indicated by number of entries to open arm were in the following order, control<leaf aqueous $400<$ leaf oil $800<$ leaf oil $400<$ leaf aqueous $800<$ diazepam (Table 2).

Table 2: Effect of HECS on number of entries to open arm of elevated plus maze; number of mice in each group.

\begin{tabular}{|ll|}
\hline Group & $\begin{array}{l}\text { Number of entries to open } \\
\text { arm }\end{array}$ \\
\hline Control & $3.67 \pm 1.75$ \\
\hline Leaf aqueous 400 & $7.50 \pm 1.87 * *$ \\
\hline Leaf oil 800 & $7.50 \pm 2.43 * *$ \\
\hline Leaf oil 400 & $7.83 \pm 1.47 * *$ \\
\hline Leaf aqueous 800 & $13.00 \pm 2.37 * *$ \\
\hline Diazepam & $16.00 \pm 1.41 * *$ \\
\hline $\mathrm{n}=6 ;$ symbol $* *$ indicates significant values at $\mathrm{p}<0.01$ vs control. \\
\hline
\end{tabular}

\section{Effect of HECS extracts on light dark arena}

Parameter 1 - time spent in bright arena. The anxiolytic potency of the extracts in LDA test as indicated by time spent were in following order, control<leaf oil $800<$ leaf oil $400<$ leaf aqueous $400<$ leaf aqueous $800<$ diazepam (Table 3).

Table 3: Effect of HECS on time spent in bright arena of light and dark arena; number of mice in each group.

\begin{tabular}{|ll|}
\hline Group & Time spent in bright arena \\
\hline Control & $14.83 \pm 5.57$ \\
\hline Leaf oil 800 & $83.00 \pm 12.96$ \\
\hline Leaf oil 400 & $115.83 \pm 5.42 * *$ \\
\hline Leaf aqueous 400 & $123.67 \pm 12.45^{* *}$ \\
\hline Leaf aqueous 800 & $151.833 \pm 15.32 * *$ \\
\hline Diazepam & $166.67 \pm 21.41 * *$ \\
\hline
\end{tabular}

$\mathrm{n}=6$; symbol $* *$ indicates significant values at $\mathrm{p}<0.01$ vs control.

Parameter 2 - number of crossings. The anxiolytic potency of the extracts in LDA test as indicated by number of crossings were in following order, control<leaf oil $800<$ leaf oil $400<$ leaf aqueous $400<$ leaf aqueous $800<$ diazepam (Table 4).

Table 4: Effect of HECS on number of crossings of light and dark arena; number of mice in each group.

\begin{tabular}{|ll|}
\hline Group & Number of crossings \\
\hline Control & $5.02 \pm 1.67$ \\
\hline Leaf oil 800 & $7.83 \pm 1.17 * *$ \\
\hline Leaf oil 400 & $9.50 \pm 1.87 * *$ \\
\hline Leaf aqueous 400 & $10.53 \pm 2.22 * *$ \\
\hline Leaf aqueous 800 & $14.17 \pm 3.87 * *$ \\
\hline Diazepam & $15.16 \pm 3.97 * *$ \\
\hline
\end{tabular}

$\mathrm{n}=6$; symbol $* *$ indicates significant values at $\mathrm{p}<0.01$ vs control. 


\section{Effects on locomotor behaviour}

\section{Photo actometer}

All oil fractions exhibited an increase in general activity which decreased with increase in dose. All aqueous fractions increased general activity with direct dose response relationship (Table 5).

Table 5: Effects of HECS on photo actometer and number of mice in each group.

\begin{tabular}{|lll|} 
Group & Dose and route & No. of movements \\
\hline Control & $0.1 \mathrm{ml} / 10 \mathrm{~g} / \mathrm{oral}$ & $82.19 \pm 11.94 * *$ \\
\hline Heiazepam & $1 \mathrm{mg} / \mathrm{kg} / \mathrm{oral}$ & $439 \pm 22 * *$ \\
oil & $400 \mathrm{mg} / \mathrm{kg} / \mathrm{oral}$ & $205 \pm 18.68 * *$ \\
\cline { 2 - 3 } $\begin{array}{l}\text { HECS leaf } \\
\text { aqueous }\end{array}$ & $800 \mathrm{mg} / \mathrm{kg} / \mathrm{oral}$ & $161.83 \pm 29.95 * *$ \\
\cline { 2 - 3 } & $800 \mathrm{mg} / \mathrm{kg} /$ oral & $306.67 \pm 10.51^{* *}$ \\
\hline
\end{tabular}

$\mathrm{n}=6$; symbol $* *$ indicates significant values at $\mathrm{p}<0.01$ vs control.

\section{Effects on motor coordination}

\section{Rotarod}

As seen from Table 6, all the animals treated with the extracts passed the cut off time 120 seconds which indicated that muscle coordination was unaffected (Table 6).

Table 6: Effects of HECS on rotarod.

\begin{tabular}{|c|c|c|}
\hline Group & Dose and route & $\begin{array}{l}\text { Retention time } \\
\text { (cut off time } 120 \mathrm{~s})\end{array}$ \\
\hline Control & $0.1 \mathrm{ml} / 10 \mathrm{~g} / \mathrm{oral}$ & $90 \mathrm{~s}$ \\
\hline Diazepam & $1 \mathrm{mg} / \mathrm{kg} / \mathrm{oral}$ & $>120$ \\
\hline $\begin{array}{l}\text { HECS leaf } \\
\text { oil }\end{array}$ & $\begin{array}{l}400 \mathrm{mg} / \mathrm{kg} / \text { oral } \\
800 \mathrm{mg} / \mathrm{kg} / \text { oral }\end{array}$ & $>120$ \\
\hline $\begin{array}{l}\text { HECS leaf } \\
\text { aqueous }\end{array}$ & $\begin{array}{l}400 \mathrm{mg} / \mathrm{kg} / \text { oral } \\
800 \mathrm{mg} / \mathrm{kg} / \mathrm{oral}\end{array}$ & $>120$ \\
\hline
\end{tabular}

s-seconds.

As per EPM and LDA test, anxiolytic property of the test materials was found to be in the following order. Diazepam $>$ CS aqueous $800>C S$ aqueous $400>C S$ oil 800> CS oil $400 \mathrm{mg} / \mathrm{kg}$. Results from photo actometer indicate that none of the extracts possess sedative property. All the extracts were devoid of adverse effects of motor coordination.

\section{DISCUSSION}

Several herbs and spices have been used for culinary purpose since ages. Traditional belief that spices and herbs possess central nervous activity, antimicrobial and metabolic effects are supported by various preclinical and clinical studies. The practice of using these flavouring agents may have originated from zoo pharmacognosy, where the self-medication by the animals either to treat or prevent disease is guided by internal drive. ${ }^{11}$ The present study was carried out to evaluate the anxiolytic activity of Coriandrum sativum. Previous studies have reported that leaf possess anxiolytic properties. ${ }^{12,13}$ These mandates for a detailed study of this plant to assess the anxiolytic activity. The constituents responsible for anxiolytic properties may have a variable distribution pattern in the different parts of the plant. The leaves were extracted using hydroethanolic solvent because of its broad spectrum of extractive value. In order to narrow down the search further, hydroethanolic extracts of leaves were divided into aqueous and oil fractions. The anxiolytic properties were assessed using elevated plus maze and light dark arena. Evaluation of the locomotor behaviour of the test compound by photo actometer was done to categorize the extract into sedative and non-sedative. Rotarod test was performed to find their effects on muscle coordination.

\section{Anxiolytic activity}

The elevated plus maze and light dark arena test are the two commonly employed animal model for anxiety. EPM is based on three anxiogenic factors-novelty, height and exploratory behaviour. The number of entries and time spent in the open arms have been found to be increased by anxiolytics and reduced by anxiogenic agents. ${ }^{13}$ The LDA test is based on the natural aversion of mice to brightly lit places. Anxiolytics reduce the natural aversion to light and increase the time spent in the light compartment. The result from EPM and LDA gives a complicated picture with mixed response which makes it quite difficult to come to a conclusion. Detailed analysis by combining the results from both anxiety models are required to solve this puzzle. In order to accomplish this, the parameters from EPM and LDA are grouped into exposure parameters (time spent in open arm/bright area) and exploratory parameters (number of entries into open arm/number of crossings) respectively.

\section{Exposure behaviour}

Exposure of the animals to high risk (open arm/brightly lit arena) zone indicates low anxiety and anxiolytic agents tend to potentiate this behaviour. This can also happen if the drug disturbs the alertness of the animal.

\section{In EPM}

The exposure behaviour was increased in following order. At $400 \mathrm{mg} / \mathrm{kg}$ : control<leaf oil<leaf aqueous<diazepam. At $800 \mathrm{mg} / \mathrm{kg}$ : control<leaf oil<leaf aqueous $<$ diazepam.

\section{In LDA}

The exposure behaviour was as follows. At $400 \mathrm{mg} / \mathrm{kg}$ : control<leaf oil<leaf aqueous<diazepam. At $800 \mathrm{mg} / \mathrm{kg}$ : control $<$ leaf oil $<$ leaf aqueous $<$ diazepam. 


\section{Exploratory behaviour}

Mice tend to avoid the open areas, especially when they are brightly lit, favouring darker and or enclosed space. ${ }^{14}$ This approach avoidance conflict results in behaviours that have been correlated with increase in physiological stress indicators. ${ }^{15}$ Administration of benzodiazepines and other anxiolytic treatments results in increased exploration of the open arms, without affecting general motivation or locomotion. ${ }^{16}$ In contrast, this behaviour can be augmented in case of fear induced hyperactivity leading to a false positive result.

\section{In EPM}

The exploratory behaviour was increased in following order. At $400 \mathrm{mg} / \mathrm{kg}$ : control<leaf aqueous $<$ leaf oil<diazepam. Both oil and aqueous part of leaf extracts exhibited moderate anxiolytic property. At $800 \mathrm{mg} / \mathrm{kg}$ : control<leaf oil $<$ leaf aqueous $<$ diazepam.

Leaf aqueous part was more potent than oil fraction. A direct dose response relationship was observed in leaf aqueous and an inverse dose response relationship with leaf oil.

\section{In LDA}

The exploratory behaviour was as follows. At $400 \mathrm{mg} / \mathrm{kg}$ : control<leaf oil <leaf aqueous<diazepam. At $800 \mathrm{mg} / \mathrm{kg}$ : control<leaf oil <leaf aqueous $<$ diazepam. A direct dose response relationship was observed in leaf aqueous and an inverse dose response relationship leaf oil.

At lower dose $(400 \mathrm{mg} / \mathrm{kg})$, leaf oil exhibited anxiogenic property and at higher dose $(800 \mathrm{mg} / \mathrm{kg})$ anxiolytic property. This indicates the presence of either anxiogenic and anxiolytic constituents or single constituents acting on multiple receptor types. The anxiogenic compound may have antagonized the effects of anxiolytic constituents or mechanism at low dose. ${ }^{17}$ At high dose, anxiolytic constituents might have superseded.

\section{Photo actometer}

Photo actometer is a closed box in which the movements of animals are recorded photoelectrically to assess the locomotor activity. ${ }^{18}$

Table 7: Activity report of HECS using photo actometer.

\begin{tabular}{|lll|}
\hline Extract & $\begin{array}{l}\text { Effect on } \\
\text { anxiety }\end{array}$ & $\begin{array}{l}\text { Sedative } \\
\text { property }\end{array}$ \\
\hline Leaf oil & Biphasic & Non sedative \\
\hline Leaf aqueous & Anxiolytic & Non sedative \\
\hline
\end{tabular}

The oil fractions exhibited an increase in general activity with an inverse dose response relationship. The aqueous fractions increased general activity with direct dose response relationship (Table 7).

\section{Rotarod}

All the animals treated with the extracts passed the test at a cut off time 120 seconds which indicates that muscle coordination was unaffected.

\section{CONCLUSION}

The results obtained in this study suggests that the hydroethanolic extracts of leaves of Coriandrum sativum at a dose of $400 \mathrm{mg} / \mathrm{kg}$ and $800 \mathrm{mg} / \mathrm{kg}$ given orally possess anxiolytic activity but with a complex pharmacodynamic profile as expressed by varying antianxiety effect with dose and screening techniques used.

After the scrutiny with the individual test analysis and the combined analysis, it is proposed that Leaf aqueous possess anxiolytic properties containing one or more compounds. None of the test extracts exhibited sedative or any adverse effect on motor coordination as indicated by photo actometer and rota rod respectively. Hence extracts of Coriandrum sativum could be better alternative to the conventional anxiolytic agents in terms of its non-sedative action. The following study design is proposed for the continuation and identification of active constituent employing the findings of the present study. LC-MS, H-NMR, C-NMR and FT-IR analysis of the fractions should be employed to identify known constituents or for structure elucidation of novel compounds.

\section{ACKNOWLEDGEMENTS}

Authors would like to thank Department of Pharmacology, Yenepoya Medical College, Derlakatte, Mangaluru, Karnataka.

Funding: No funding sources

Conflict of interest: None declared

Ethical approval: The study was approved by the Institutional Animal Ethics Committee

\section{REFERENCES}

1. James M, Donnell O, Shelton RC. Drug Therapy of Depression and Anxiety Disorder In: The Pharmacological Basis of Therapeutics, 12th edition, McGraw Hill New York; Goodman and Gillman; 2011:398-413.

2. World Health Organization. The World Health Report 2001: Mental Health: New Understanding New Hope. World Health Organization, Geneva, ISBN: 9789241562010; 2001:182.

3. Reynolds EH. Brain and mind: a challenge for WHO. Lancet. 2003;361:1924-5.

4. Gogte VM. Ayurvedic Pharmacology and Therapeutic use of medicinal plants 
(Dravyagunavigyan), 1st edition. Ramakrishna, Executive Secretary, Vidya Bhavan, Kulpati, Mumbai; 2000: 405-406.

5. Wallis TE. Textbook of Pharmacognosy, 5th edition, Jain SK for CBS pulishers and distributors, New Delhi; 2005: 125-126.

6. Mir H, Sativum CL. Application of plants in prevention and treatment of illness. Persian. 1992;1:252-7.

7. Zhang ZJ. Therapeutic effects of herbal extracts and constituents in animal models of psychiatric disorders. Life Sci. 2004;75:1659-99.

8. Vogel GH. Drug Discovery and Evaluation: Pharmacological Assays. 2nd ed., Vol. 434. Berlin: Springer; 2002:622-628.

9. Kulkarni SK. Handbook of Experimental Pharmacology. 3rd ed. Chandigarh: Vallabh Publications; 2012.

10. Medhi B, Prakash A. Animal experiments on central nervous system. In, Practical Manual of Experimental and Clinical Pharmacology 1st edition. New Delhi. Jaypee Brothers Medical Publishers; 2010:183-186.

11. Masoumeh E, Mohammed K, Maryam FA. Coriandrum sativum: Evaluation of its anxiolytic effect in elevated plus maze. J Ethanopharmacol. 2005;96:365-70.

12. Harsha SN, Anilkumar KR. Effects of Coriandrum sativum extract on exploratory behaviors pattern and locomotor activity in mice: an experimental study. Int J Green Pharm. 2012;6:157-62.
13. Latha K, Rammohan B, Sunanda B, Maheswari UMS, Mohan SK. Evaluation of anxiolytic activity of aqueous extract of Coriandrum sativum Linn.in mice: A preliminary experimental study. Phcog Res. 2015;7(1):47-51.

14. Gonzalez LE, File SE. A five minutes experience in the elevated plus-maze alters the state of the benzodiazepine receptor in the dorsal raphe nucleus. Official J Society Neurosci. 1997;17:1505-11.

15. Belinda JC, Margrit H, Dieter S, Mario K, Graham HJ. Effects of benzodiazepine receptor partial inverse agonists in the elevated plus maze test of anxiety in the rat. Psychopharmacology. 1995;121:118-26.

16. Byrne RPP, Katon W, Cowley DS, Russo J. A Randomized effectiveness trial of collaborative care for patients with panic disorders in primary care. Arch Gen Psychiatr. 2001;58:869-76.

17. Nemertoff CB. Anxiolytic past, present and future agents. J Clin Psychiatry. 2003;64:3-6.

18. Tedeschini E, Fava M, Papakostas GI. Placebo controlled antidepressant clinical trials cannot be shortened to less than 4 weeks duration. J Clin Psychiatry. 2011;72:98-118.

Cite this article as: Puthallath RE, Kotekar S, Rao SN, Narayana MR, Nayak RP. Effect on anxiety of Coriandrum sativum leaf hydroethanolic extract oil and aqueous fraction in swiss albino mice. Int $\mathrm{J}$ Basic Clin Pharmacol 2020;9:1032-7. 